centre where Spanish and foreign biologists were able to find modest accommodation and good laboratory facilities amidst unspoilt Nature. This long and fruitful activity was rudely interrupted when at the age of ninety Bolivar became an exile, followed by a group of his colleagues. It was characteristic of Ignacio Bolivar and his younger followers that in Mexico they should take a most active part in the scientific life of the country of their adoption, and are contributing greatly to its scientific exploration. A monthly journal, Ciencia, launched by them, rapidly became a widely known medium of biological knowledge in Latin America.

Although Bolivar published some papers on the Hemiptera, on other insect orders and on Crustacea, he specialized from his earliest days on the systematics of the Orthoptera, a group particularly well represented on the Iberian peninsula, where it includes a high proportion of endemic genera and species. The total number of papers published by Bolivar was about two hundred and thirty, and he described more than two hundred new genera and about a thousand species of Orthoptera. His work on this order partly coincided in time with that of Brunner, Saussure, Pictet and Redtenbacher, and he is to be included with them as a creator of the modern system of Orthoptera.

While a great deal of Bolivar's work was purely descriptive, we owe to him also a series of revisions and monographs, and his works on the Tetrigidx, Pamphaginæ, Pyrgomorphinæ, Truxalinæ and Ephippigerinæ, still remain indispensable for a taxonomist. From the faunistic point of view his main contribution was, of course, to the study of the Iberian fauna, but he ranged widely in his work, from India to the Seychelles and from the Congo, Angola and Spanish Guinea to South America.

Most present-day orthopterists regard Ignacio Bolivar as their master and it was a great and touching occasion when in 1935, during the Sixth International Entomological Congress at Madrid, a group of some fifteen orthopterists of various nationalities gathered round him for a 'family' celebration. For those who knew Don Ignacio personally, it was impossible not to fall under the spell of his vital personality, full of noble and simple charm. His energy was prodigious, and I shall never forget an excursion to the highest peak of Sierra de Guadarrama, when Don Ignacio, then well over seventy years old, led the way on foot for several hours.

The value of Bolivar's work was recognized by the Entomological Societies of London, Belgium and Prague, which elected him honorary fellow, while the Zoological Society of London included him among its twenty-five foreign members. Among many other academic distinctions, he was a doctor honoris causa of the University of Pittsburgh. B. P. Uvarov.

\section{Dr. G. C. Robson}

Guy Colborn Robson, whose death occurred on May 17, 1945, after a long illness, was born at South Woodford, Essex, on February 11, 1888. He obtained a Classical Scholarship at New College, Oxford, where he entered into residence in 1906. He took Classical Moderations, and then changed over to science, reading for honours in zoology, in which he obtained a first class, and afterwards spent a year in Naples, where he studied the fat-metabolism of crabs infested with Sacculina. He joined the staff of the British Musoum Natural History in 1913 and was put to work on the Mollusca under Edgar Smith. He became a well-known authority on this group and devoted much attention to their anatomy, as well as the 'conchology' on which earlier classifications were mainly based. He published numerous papers, mainly on the Cephalopoda, including perhaps his most important work, a monograph on the Octopoda, published by the British Museum in two volumes (1929 and 1932). He also studied the biology of Paludestrina jenkinsi, a parthenogenetic freshwater snail introduced into Britain some time during the eighties of last century, and now widely distributed throughout Britain.

Robson was attracted to zoology from the philosophical side and it is doubtful whether he was entirely happy in his museum life. His intellectual interests were many and varied-artistic, literary, sociological, philosophical. The latter bent is best shown in his two books, "The Species Problem" (1928) and (jointly with O. W. Richards) "The Variation of Animals and Plants in Nature" (1936). His artistic gifts are evident in the illustrations to his papers and also in his water-colours.

During the War of 1914-18, he served first with the Red Cross and then with the Royal Garrison Artillery and was attached to a coast defence unit. $\mathrm{He}$ was bombed during an air attack, and, after spending a year in hospital suffering from shell-shock, was invalided out of the service. He returned to the British Museum, where he spent some of the most productive years of his life and became a deputy keeper. Unfortunately, he never seemed to have recovered fully from his illness, and in 1935 had another nervous breakdown necessitating his resignation from the Museum. He spent the last few years of his life in retirement.

\section{Some Czechoslovak Men of Science}

News has just reached London that several more Czechoslovak professors, displaced when the Germans closed the universities of that country in 1939, have died in concentration camps. They include Prof. V. Dolejšek, Prof. F. Ulrich and Prof. J. Storkán. Prof. F. Slavík, a mineralogist well known in Britain and now sixty-nine years old, was rescued from Buchenwald by the Allies just in time, and has now been able to travel to Prague. The fate of Prof. F. Záviška, the physicist, is unknown; he has not yet been traced.

It is now known that Prof. A. Símek, whose death has already been referred to in Nature (152, 69; 1943), was executed at Mauthausen concentration camp.

Prof. Dolejšək was a distinguished physicist who worked for a time with Prof. Manne Siegbahn in Uppsala. Some of his work on X-ray spectra was first published in Nature, and he is perhaps best known for his discovery of the $N$-series of X-ray lines. He died at the Terezin camp in January last.

Prof. F. Ulrich had carried out many mineralogical investigations of considerable local interest and had made important petrographic and geological studies. $\mathrm{He}$ was also the author of several authoritative treatises on geology and had been elected honorary foreign member of numerous European scientific societies.

Prof. Storkán had a distinguished career as a zoologist and was an authority on the Central European fauna. He was only fifty-four at the time of his death.
G. Druce. 